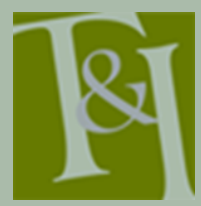

The International Journal for Translation \& Interpreting Research

trans-int.org

\section{Innovative interpreting: iPad technology as a bridge to interpreting services in a post- secondary setting}

\author{
Suzanne Ehrlich \\ University of Cincinnati \\ suzanne.ehrlich@uc.edu
}

Katherine Vance

University of Cincinnati

vanceki@ucmail.uc.edu

DOI: 10.12807/ti.107202.2015.a05

\begin{abstract}
As the presence of mobile technologies continues to emerge in our everyday lives, so do situations that demand immediate interpreting services in postsecondary settings. Access to interpreting has not always been easy, and with the invention of mobile technologies comes an opportunity to build a largely unprecedented bridge to this service. This study was designed to gain an overview of how users of interpreting services on a daily basis employ technology for accessing education through their use of on-demand interpreting via iPad technology. This paper will highlight the success and challenges of implementing technology in a post-secondary setting. Initial findings outline the complexity of implementing on-demand, remote services in post-secondary settings, and highlight a gap worthy of further exploration to improve interpreting services for deaf and hard of hearing post-secondary students.
\end{abstract}

Keywords: iPad, technology, interpreting, disability, access, deaf, post-secondary.

\title{
Introduction
}

The use of technology to provide communication access to users of a signed language is not a new concept. Services including the use of Communication Access Realtime Translation (CART) or C-Print, note-taking, and text messaging are just a few of the ways in which technology has increased access to information for signed language users. Additionally, recent changes in legislation in the United States (U.S.) in association with video remote interpreting (VRI) - a fee-paying service similar to on-site interpreting and paid for by the requesting client (RID Video Interpreting Committee, 2008) - allow for greater communication access to signed language users. VRI services enable signed language users to connect with the interpreter via a video platform that utilises video conferencing equipment. VRI services can be utilised in an ondemand fashion or can also be pre-scheduled. VRI providers charge a perminute premium for services and often require a specific minute minimum (RID Video Interpreting Committee, 2008).

Since the 1970s, the United States has enacted several significant pieces of legislation providing deaf and hard-of-hearing individuals with access to education and employment. The Rehabilitation Act of 1973 was the first civil 
rights legislation that afforded protection to and prohibited discrimination against individuals with disabilities seeking employment and education. The Rehabilitation Act (1973) made it illegal for individuals to be discriminated against on the basis of disability. The definition of disability as outlined in the Rehabilitation Act (1973) is a "physical or mental impairment that constitutes or results in a substantial impediment to employment" (29 U.S.C.S. § $705(9)(B))$. One limitation of the law is that it applies to federal agencies, agencies or programs receiving federal funding, federal employment, and businesses with federal contracts; therefore, private businesses and educational institutions did not have to comply with the law.

The passage of PL 94-142 (Education of All Handicapped Children Act) in 1975 began the process of breaking down barriers to free and appropriate public education (FAPE) for children with disabilities. Deaf and hard-of-hearing children were, therefore, also afforded opportunities to access education through the public school system. In 1995 members of the general education community decided it was time to "transform it from an access law to a quality and an outcomes statute" (Itkonen, 2007, p. 11). Subsequently PL 94-142 was reauthorised in 1997, then again in 2004 and enacted as the Individuals with Disabilities Education Improvement Act (often referred to as IDEA). Congress determined that "ensuring equality of opportunity, full participation, independent living, and economic self-sufficiency for individuals with disabilities" (20 U.S.C.S. $§ 1400(c)(1))$ should be a priority in enacting national policy.

The Americans with Disabilities Act (ADA) (1990) was a monumental law that intended to eliminate discrimination against individuals with disabilities by providing enforceable standards that addressed discrimination on the basis of a disability. The ADA (1990) filled in the gaps left by the Rehabilitation Act (1973) by requiring compliance for entities, whether private or public, in areas of employment, public services, public accommodations and services operated by private entities, and other miscellaneous provisions. Through the provisions granted in the ADA (1990), individuals with disabilities, and more specifically those who are deaf or hard of hearing, have since been afforded the opportunity for reasonable accommodations at institutions of higher education and in the workplace.

Title IV of the ADA (1990) finally mandated telecommunication accessibility for those who are deaf or hard of hearing and persons with speech disabilities (Yoshida, 2008). These provisions led to the establishment of Video Relay Services (VRS) which are regulated through the Federal Communications Commission (FCC). VRS services, and subsequently, VRI (which unlike VRS services are not regulated or mandated by the FCC), changed the landscape in which signed language interpreters provide services and how signed language users communicate with one another. Unfortunately, one particular limitation of VRS services is that the signed language user and the hearing party to whom they are communicating cannot be positioned in the same room. This particular limitation eliminates the use of federally funded VRS services to individuals needing immediate, real-time, visually dynamic interpreting services.

In other arenas, for both professional and personal use, alternative approaches to communication have been tested. One involves the use of computerised systems, including mobile technologies, to communicate within the context of classrooms (Henderson \& Yeow, 2012). While technology has successfully enabled many to adapt to service demands, this option remains in its infancy and has yet to be proven as a sufficient substitute for the presence of a qualified interpreter as primarily used today (Schuler, Mistler, Torrey, \& 
Depukat, 2013). In the current base of emerging literature surrounding remote interpreting, the issues have often been linked to challenges in turn-taking (Simon, Hollrah, Lightfoot, Laurion \& Johnson, 2010), establishing a visual presence for an increased sense of connection between users (Ehrlich-Martin, 2006), and reducing barriers of social isolation and interpersonal communication (Shaw \& Roberson, 2013). As highlighted by Shaw \& Roberson's recent study on social disconnectedness of deaf retirees (2013), rapid changes with technology have resulted in a reduced need for connecting geographically and 'meeting' in the traditional sense of the word.

In other recent studies of sign language interpreting, data has been collected to better understand the potential impact of technology on deaf communities (Rusell \& Demko, 2013). During an environmental scan, Russell and Demko (2013) found that technologies and government support programs offer the opportunity to reduce isolation among community members who wish to gain greater access to information via technology. Studies such as theirs offer a glimpse into the potential that technology holds to increase access for individuals whose engagement may be limited due to location, language, and other common barriers. These findings can be particularly useful for institutions situated in rural communities, or for campuses with small numbers of deaf or hard of hearing students.

Mobile technology, while innovative, is still not without its challenges. From Wi-Fi to security, for all users the world of mobile access requires a body of research to support its practice, thus leaving us with the question: can mobile technologies feasibly provide opportunities for interpreting services outside of VRS or VRI? Moser-Mercer (2005) acknowledged that "interpreters have not yet been trained to work in remote settings and are thus still having to rely largely on consciously controlled processing" (p. 77). This, among many other challenges, presents us with the task of gaining a better understanding of how participants utilising remote interpreting services are being impacted. Results from past and current research can also play a critical role in shaping and supporting interpreter education for preparing future interpreting professionals (Alley, 2012).

This case study employs piloting with pre-scheduled interactions to explore the concept of direct versus indirect on-demand interpreting, with the goal of developing a framework of considerations when offering on-demand interpreting services. Identifying necessities or constraints for on-demand services provides not only evidence of practice, but an entirely new approach to interpreting services driven by the demands of our environment and community. We also hope to answer the question: what factors should be considered when providing successful interpreting services via iPad?

\section{Methods}

This case study was conducted at a large, Midwestern, urban university in the U.S. with a yearly average deaf and hard of hearing student population of approximately 14 students. There is no known current (2008 or later) data on the average deaf and hard of hearing population enrolled in U.S. post-secondary institutions. The sampling method employed for this phase of the study was convenience sampling due to the limited number of available participants. More specificially, one participant emerged as the primary focus of the study for this phase. The participating student was accepted not only for convenience, but also because of his hearing status (self-identified as hard of hearing) and willingness 
to participate. All participants were unpaid; however, they were provided with an iPad throughout the duration of the study. The exercise was developed as a case study (Kin, 2014) to explore the use and impact on student perception of interpreting services via iPad. This particular method was used to assist with testing our instruments (surveys). The study was initially submitted to the institution's review board for approval, and granted exempt status. While exempt status does not require the secure methods to collect data that were employed in this case study, investigators nonetheless adhered to the same standard of research practice expected in non-exempted research, which included informed consent and non-disclosure agreements. The student was a junior majoring in biomedical engineering, who was prepared to use interpreting services not only to take classes, but also remotely during his out-of-state cooperative placement.

Phase I of the case study consisted of two parts: 1) the collection of data surrounding the participants' (student and interpreter) experiences using the iPad to access and/or provide interpreting services in a post-secondary setting, and 2) further data collection of experiences in connection with iPad interpreting services in the student's professional cohort work conducted out-of-state in the U.S. During the initial stages of the case study in the fall semester of 2012, the student and the lecturer of the undergraduate, professional cohort course gave their informed consent to participate. The student took a pre-service survey (see Appendix 1) that assessed his use of technology in both his personal and academic life, and included a guarantee of anonymity with the option of selfdisclosure. Additionally, demographic information including gender, hearing status, and education were collected. The survey design was based on a previously conducted iPad study at Pepperdine University (n.d.) The Pepperdine University iPad research study methodology website ${ }^{1}$ provides documents ranging from the surveys - adapted for this study - to waivers and agreements for iPad project implementation. The identified lecturer of the respective undergraduate, professional cohort course signed an informed consent to participate in the study, but was not provided with a pre-service survey. (Lecturers were given the informed consent agreement due to data being collected in their classrooms, which included interactions with and because of their teaching).

Part one of the first phase of the case study was conducted by providing remote interpreting services for a one-hour course the student was taking in a large auditorium-style classroom. Both the student and the interpreter used iPads of varying generations $\left(2^{\text {nd }}\right.$ and $\left.3^{\text {rd }}\right)$, to connect with one another on the FaceTime platform - an Apple-based videoconferencing software tool, utilised by oncampus Wi-Fi services. The iPads used in the case study included an iPad purchased by the institution and loaned to the student, and the researcher's personal iPad.

While the student sat in the classroom, the interpreter positioned herself outside in the hallway. This action was taken purposely, in order for her to remain physically accessible and provide face-to-face interpreting services if the technology failed - thereby ensuring compliance with the law requiring such services to be offered. (In the U.S., federal legislation mandates the allocation of interpreting services to signed language users who are registered with the disability services office at their respective institution. If the technology failed and the researcher or another interpreter was not immediately available to provide interpreting services, then the university would be in direct violation of

\footnotetext{
${ }^{1}$ http://community.pepperdine.edu/it/tools/ipad/research/docs/default.htm

Translation \& Interpreting Vol 7 No 2 (2015)
} 
federal law). The internal microphone on the iPad picked up audio. The interpreter listened to the audio with and without headphones, to better observe and experience the effects of both modalities on the quality of service. Observations of the interpreting exchange were documented by the second researcher utilising a matrix whose development was based on the Pepperdine University (n.d.) study. In this context, the student, interpreter, and observer debriefed after the class meeting to discuss their perceptions and experiences. These were documented both via direct observation as well as through reflections in the post-survey.

After several attempts, which included regular class sessions interpreted via the iPad positioned outside of the classroom, the interpreter moved to an oncampus location in a different building while providing interpreting services for the student's class. The second researcher, who acted as the observer, remained in the classroom with the student to document observations of the interpreting exchange and to provide backup interpreting should the technology fail. Remote interpreting services continued for the duration of the semester until the student completed his coursework.

In the spring of 2013, as Part 2 of the first phase of the study, the student relocated out-of-state to participate in cooperative employment as required by his degree program at a mid-sized, private business on the U.S. West Coast. Arrangements were made prior to the student's departure in order to utilise the iPad for remote interpreting needs during his cooperative placement. The researchers ensured the student had necessary charging equipment, as well as any generic passwords needed for periodic device software updates.

Furthermore, the researchers worked with the student to reach agreements with the employer for using the interpreting services during any workplace meetings that discussed proprietary information. The researchers, interpreters and student participant all signed non-disclosure agreements and worked with the employer to determine which meetings would require the use of interpreting. Considerations for this particular student included persons attending meetings by telephone, speakers with accent variations, length of meeting, and topic of discussion. These considerations were made based on the information provided by the student participant and prior work experience in this setting. Several standing meetings were then identified based on the information provided and the student participant's prior work experience at this location. The interpreter was then scheduled to provide remote interpreting services. Particular allowances were made for the location in which the interpreter would provide interpreting services, as the student and the interpreter were located in different time zones (Pacific Standard Time (PST) and Eastern Standard Time (EST)). During the student's cooperative employment he utilised remote interpreting services at scheduled times and made two last-minute requests for services. The interpreter provided interpreting services from her office on the institution's campus, and from home. In two instances, a team of interpreters was used to provide remote interpreting services for longer meeting requests. Wi-Fi connectivity varied based on participant placement, i.e. home or office. While the Wi-Fi levels varied, all users reported having acceptable functionality with the occasional disruption. The introduction of new participants, who were also required to sign informed consents and non-disclosure agreements, poses a new complication in consistency and potential challenges. The use of remote interpreters is limited in Phase I of this project, and has not yielded enough data to discuss at length.

At the end of each interpreting session - both on-campus in the fall of 2012, and during the student's co-operative employment in the spring of 2013 - the 
interpreter completed reflections about the interpreting experience, documenting duration of the call, Wi-Fi connectivity, technology used, challenges related to the particular experience, and other noted observations. Additionally, after finalising his co-operative employment the student completed a post-service survey (See Appendix 1), which was again adapted from the Pepperdine study (n.d.). A post-service survey (See Appendix 2) was also sent to the student's supervisor, which surveyed the supervisor's perception of the use of the technology and its impact on the student's performance in the workplace. The post-surveys (Pepperdine University, n.d.) were both very similar for consistency, with only minor modifications based on either the student participant as the subject or the supervisor as the subject.

\section{Results}

This study examined perceptions and experiences of participants' use of iPad technology to access interpreting services. This section will present the findings from observations, surveys (see Appendices), and reflections collected during Part 1 and 2 of the first phase of the case study; Part 1 of the classroom-based experience; and Part 2 during the professional cohort experience. Themes reported below were identified during line-by-line open-coding analysis conducted by the research team. The ways in which the iPad has been used to access services as well as challenges encountered will also be explored.

Prior to the integration of this study, interpreting services via iPad were delivered only through the use of a live interpreter at the setting/site. After discussion within both the academic unit and the disability services office, both agreed to initially use the iPad technology with the goal that it would provide a common platform for both device and software, requiring little from the research team and participants to maintain. For this phase of the study, only iPad technology was used with the FaceTime application. No other software was explored or reviewed during this phase.

\section{Surveys}

Upon review of the pre- and post-surveys (see Appendices), both the supervisor and student noted a positive perceived impact on the hard of hearing student's performance in the workplace. This was noted both in the Likert-scale survey items, as well as in the open-ended, qualitative statements in the survey. Additionally, the student noted he would very likely use the iPad in the future and would recommend the iPad to others. The following comment from the supervisor to the question "Did the use of the mobile technology change your perception of your employee? Why or why not?" revealed one of the most powerful changes in perception from the experience:

The employee had interned with us before without using the iPad, so I already knew the individual quite well. Interestingly, people perceived the employee as being more participative in meetings with the iPad. One change that was noticeable when the employee started using the iPad was that they were more engaged in meetings that were taking place online or over the phone. It made it easier for them to follow the conversation in a challenging listening environment. (Response to Supervisor Survey Q.6).

\section{Technology}


Connectivity, as anticipated, became a significant theme throughout the case study. Both successful and unsuccessful experiences were documented during the scheduled observations. One of the primary technical complications came from difficulty accessing consistent and stable Wi-Fi in the various settings (classroom, board rooms, etc.). Audio was also compromised for the interpreter who was at a distance (not in the same room) when the student did anything physical near the iPad. While video was, by default, impacted by the Wi-Fi signal, the interpreters did not code video quality as a primary technical issue during the observations. The interpreters indicated in the reflection forms that when the iPads maintained connectivity the quality was stable enough to provide services. However, it was during the instances when the iPads disconnected due to poor Wi-Fi signal that the screen froze making it impossible to see one another. When the screen froze the interpreter and the signed language user were no longer able to communicate with one another, and therefore the sign language user lacked sufficient communication during the scheduled interpreting event.

\section{Physical}

The physical impact and demands of the interpreting work via the iPad surfaced as a primary theme. Observations revealed that there were consistent issues with adapting the use of the iPads to environmental demands such as the need to connect to the team interpreter, the iPad's serving as a physical distraction to others witnessing the process (peers of the student), and the signing space. Signing space surfaced as one of the primary challenges due to the fact that the video camera required the interpreter to adjust their body to accommodate the camera capturing range on the iPad (see Figure 1 below).

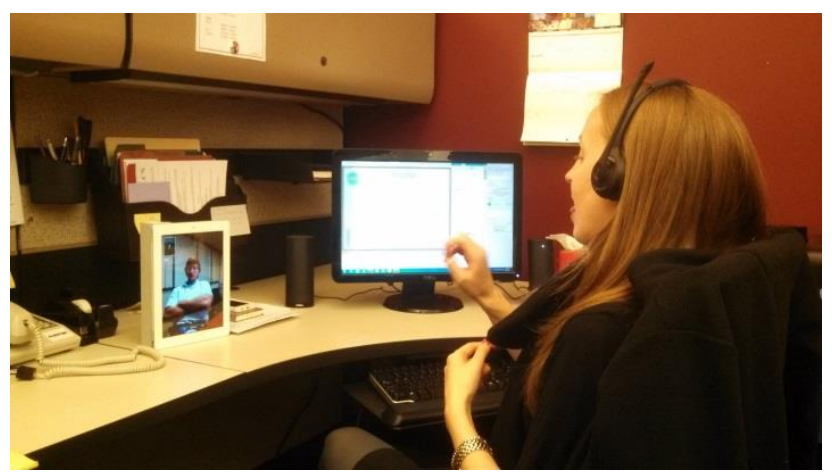

Figure 1. (Interpreting services via iPad technology, 2013).

\section{Inconsistency}

One unexpected theme which emerged from the descriptive coding process highlighted noticeable challenges regarding preparation (and lack thereof), and connectedness. While connectivity from a technical perspective was discussed above, this theme pointed more toward the feeling of disconnection noted in the analysis of the transcripts between the interpreter and the student. At this point in the case study, there is no further data to explain how connectedness may or may not have impacted the process and experience for participants. Preparedness also emerged as a common theme throughout the coding process. Preparedness, in this case, does not refer to any inability of the interpreters to prepare, but instead to the lack of opportunity for them to connect with others at the site where the student accessing the interpreting services. The interpreters noted that in traditional practice, they would have the opportunity to approach a speaker or other participants who may have had additional information for the event, but 
when interpreting via iPad, that opportunity became more difficult, and sometimes simply absent.

\section{Discussion}

As the literature outlines, interpreting services form a vast topic, but it is still important to find a way to support and understand the need for on-demand interpreting when both parties (signed language users with those that do not sign) are in the same location. This case study provides the framework for considering various essential aspects of such a service, including a) technology; b) support from participating entities (managers, teachers, service providers, etc.); and c) impact on participants' perceptions of service.

The challenges faced when providing services were not necessarily limited to technological access, but were also user related. Since the student could control the camera view on the FaceTime application, he would switch to reverse-view, making it potentially distracting for the interpreter since she could no longer see the client. On the other hand, the view changer helped when the interpreter needed to see what was being projected in class. While this is an isolated event, the very idea that the user has the ability to manipulate the technology does bring about new questions for discussion in the second part of the first phase of the project.

The everyday distractions were also something we did not anticipate. This included background sounds such as phones ringing, conversations outside cubicles, students typing on their laptops, and more. We are interested in exploring further how a microphone might change the level of distractions as well as how location might reduce their number. As was noted earlier, we initially tested sound with and without headphones to better understand what the interpreter would experience.

In respect to location, we hope to adjust expectations about what is most conducive, but not to a point that eliminates the possibility of using such services for on-demand needs. If on-demand need is one of the drivers of using such a service, then we must further explore how to adapt to distractions rather than focus on how to manipulate them.

As demonstrated above, the survey data proved to be fruitful in regard to perception, from both the employer and the student perspective. Our confidence in the success of this project is partly due to the employer's response that they found the student to be more engaged during the cooperative experience as a direct result of having on-demand services delivered via the iPad. Data in regard to perception is still very limited, but Phase 2 of this study will focus more heavily on perception from numerous data sources including, but not limited to, students, interpreters, employers, and teachers.

This case study had led us to consider four primary areas for our next phase: technology, material needs, perception, and frequency/type of use of on-demand services. The four themes emerged during line-by-line open coding analysis conducted by the research team. While the project will focus heavily on these four themes, we will also be attentive to the emergence of new demands with an increase in sample size in Phase 2 whilst understanding that one challenge of open-coding is the potential for researchers to miss an important concept.

Through review of the data, the use of iPads and mobile technology to access interpreting services posed the question of whether on-demand services no longer limited by geography would enhance service quality, simply by affording access to a larger pool of interpreters. Additionally, by conducting 
Phase 2 of this study, the goal will be to establish and disseminate a standard of practice for future communities, both rural and suburban, to consider what impact such services could have on community members and perceptions, as well as on the quality of interpreting services and connectedness. This can be further studied by examining participants' perception of social connection and, even further, their notions of effective and successful communication using remote, on-demand interpreting services. As we move further through this study, we will continue to explore alternative devices and applications to examine whether any differences may exist in the available hardware or software that would either support or hinder such services. This phase of the study in particular is not generalisable, but does offer transferability for those considering implementing similar initiatives.

In Phase 2 the survey design will not only include various participants, but will also focus on numerous other concepts, including how demand-control schema practice (Dean \& Pollard, 2009) plays a role in interpreter decisionmaking in on-demand interpreted environments. With the many factors that do or may impact the physical work of interpreters in this environment, it is equally important to examine how decision-making may or may not change as a result of on-demand remote interpreting. In addition, systematic training and integration of iPad use, in relation to this study, to maximise efficiency and effectiveness (Napier, Song, \& Ye, 2013) will also be considered. Final considerations for future research also include the implications, changes and issues concerning the remuneration and pay matrix of contract interpreters who consent to participate.
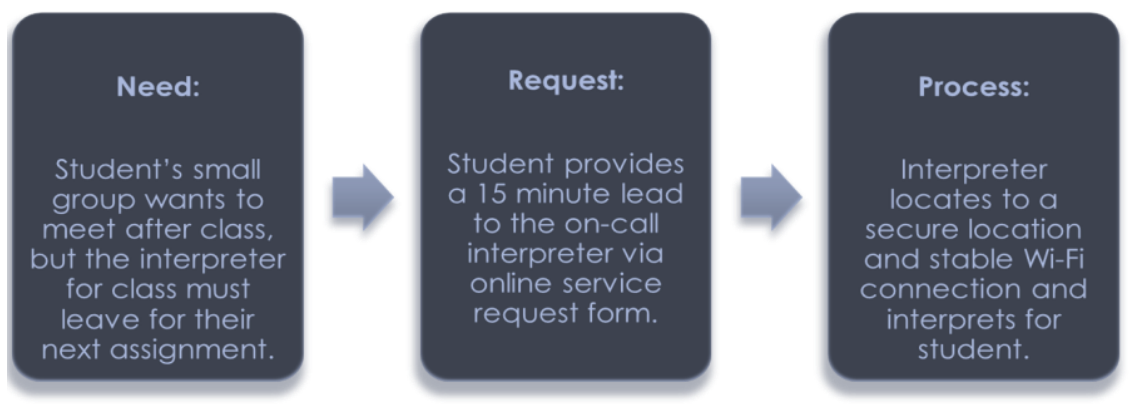

Figure 2. iPad Interpreting On-Demand Model. The process is constructed as a guideline based on the three identified domains necessary to deliver services.

\section{Conclusion}

U.S. legislation has opened the door to the use of technology in both university and workplace settings, in order to provide accessibility to individuals with varying disabilities, including those who utilise sign language and interpreting services. The findings during this initial case study demonstrate one relatively successful instance, as indicated from the pre- and post-survey data, whereby an individual who demonstrated an above-average level of comfort utilising technology in other facets of his life, used it to bridge services for interpreting. With further research and adaptation, the implementation of remote interpreting services through the use of an iPad (and foreseeably other mobile platforms) will allow greater access to communication events for signed language users, yielding a potentially positive impact both on their own participation and on others' perception of involvement. The use of the iPad for remote interpreting 
services also allows institutions to by-pass costly VRI services and set rates more closely related to those in the local market. Moreover, initiatives such as this provide opportunities for on-demand, video-based, interactive communication events where an on-site interpreter may not be available and VRS cannot be accessed due to federal regulations.

In order to identify the optimal conditions for providing remote interpreting services, there is need for further research incorporating diverse populations of signed language users and signed language interpreters for greater applicability. Additionally, a closer look at the impact of training for departmentally provided community services (such as disability services), could serve as a valuable voice for informing the development of such initiatives from a community perspective. Other opportunities for input from the institutions, departments, and programs involved in serving and supporting students through technology could prove fruitful in the search for improvement. Future research focused on the potential impact and implementation of mobile interpreting services may facilitate opening more avenues for providing signed language users with improved accessibility, both in and out of the classroom.

\section{References}

Alley, E. (2012). Exploring Remote Interpreting . International Journal of Interpreter Education, 4(1), 111-119. Retrieved from http://citasl.org/IJIE/2012_Vol4/PDF/9-Alley.pdf

Americans with Disabilities Act of 1990, 42 U.S.C.S. § 12101 et seq.

Americans with Disabilities Act of 1990, 42 U.S.C.S. § 12103(1)(A) et seq.

Ehrlich-Martin, S. M. (2006). A case study of an American sign language course taught via videoconferencing (Doctoral dissertation, University of Cincinnati).

Pepperdine University. (n.d.). iPad Documents and Forms. Retrieved from https://community.pepperdine.edu/it/tools/

Dean, R., \& Pollard, R. Q. (2001). The application of demand-control theory to sign language interpreting: Implications for stress and interpreter training. Journal of Deaf Studies and Deaf Education, 6(1), 1-14. http://xa.yimg.com/kq/groups/14491679/541650665/name/Application_of_DC_Theory.pdf

Henderson, S., \& Yeow, J. (2012, January). iPad in education: A case study of iPad adoption and use in a primary school. Proceedings of the 45th Hawaii International Conference on System Sciences (HICSS 2012), 78-87. IEEE. Retrieved from http://sarahhenderson.info/wpcontent/uploads/2013/07/2012HICSS-iPad-in-Education.pdf

Hoover, D, \& Valencia, J. (2011). iPads in the Classroom: Use, Learning Outcomes, and the Future. Presentation, 2011 EDUCAUSE Annual Conference. Philadelphia, PA. October 20. Retrieved from http://www.educause.edu/sites/default/files/library/presentations/E11/SESS081/ iPads\%2Bin\%2Bthe\%2BClassroom.pdf

Itkonen, T. (2007). PL 94-142: Policy, Evolution, and Landscape Shift. Issues in Teacher Education, 16(2), 7-17. Retrieved from http://files.eric.ed.gov/fulltext/EJ796232.pdf

Moser-Mercer, B. (2005). Remote interpreting: The crucial role of presence. Bulletin VALS-ASLA, 81, 73-97.

Napier, J., Song, Z., \& Ye, S. (2013). Innovative and Collaborative Use of iPads in Interpreter Education. International Journal of Interpreter Education, 13. Retrieved from http://cit-asl.org/IJIE/2013_Vol5(2)/PDF/IJIE\%20Vol5(2)complete.pdf\#page $=17$

Rehabilitation Act of 1973, 29 U.S.C.S. § 705(9)(B) et seq. 
Rehabilitation Act of 1973, 29 U.S.C.S. § 794 et seq.

Russell, D., \& Demko, R. (2013). Reducing the Social Isolation of Rural Deaf Albertans. Shaw, S., \& Roberson, L. (2013). Social connectedness of Deaf retirees. Educational Gerontology, 39(10), 750-760. Retrieved from http://www.tandfonline.com/doi/abs/10.1080/03601277.2012.734165\#.Uwtr1e N_uSo

Shuler, G. K., Mistler, L. A., Torrey, K., \& Depukat, R. (2013). Bridging communication gaps with the deaf. Nursing 2013, 43(11), 24-30. Retrieved from http://nursing.ceconnection.com/nu/ovidfiles/00152193-201311000-00009.pdf

Simon, J., Hollrah, B., Lightfoot, M., Laurion, R., \& Johnson, L. (2010). Steps Toward Identifying Effective Practices in Video Remote Interpreting 2010 REPORT. Retrieved from http://www.interpretereducation.org/wpcontent/uploads/2011/06/VRIStepsReportApril2010_FINAL1.pdf

U.S. Department of Health and Human Services. (n.d.). Your Rights Under Section 504 of the Rehabilitation Act. Retrieved from http://www.hhs.gov/ocr/civilrights/resources

Video Interpreting Committee (VIC). (2008, June). Video Relay Service and Video Remote Interpreting: What's the Difference? Views, 2008, 7-8. Retrieved from http://files.rid.org/articles/0608_VRS_VRI.pdf

Yin, R. K. (2014). Case study research: Design and methods. Sage publications.

Yoshida, M. (2008). Barriers for telecommunication accessibility and needs assessment of video relay services (VRS): Utilization of VRS for the deaf community. ProQuest. Retrieved from https://ritdml.rit.edu/bitstream/handle/1850/6923/MYoshidaThesis072008.pdf? sequence $=1$ 


\section{Appendix 1. Student Pre and Post Surveys}

\section{Personal Information (pre and post):}

- Age group

- Gender

- Hearing status

- Ethnicity/race

- Level of education

- Level of access to wireless internet

- Housing status

- Enrollment status at the university

- Years attended at university

- Name (optional)

\section{Pre-survey of experience and proficiency with technology in education and personal life.}

1. Do you own a...

- Desktop computer

- $\quad$ Laptop computer

- Mobile phone with internet browsing capability

- $\quad$ Light, portable computer device (netbook, iPad, Kindle, etc.)

2. If you own a desktop or laptop computer (or both), which would you consider your primary computer?

3. If you own a mobile phone with Internet browsing ability, what type of software runs the phone? Note: if you own more than one Internetcapable phone, please answer for what you consider your "primary" phone. [Circle one answer only]

- Apple (iPhone)

- Blackberry

- Google/Android

- Other

4. If you own a mobile computing device, which device(s) do you own?(Click all that apply)

- Netbook

- iPad

- Kindle

- Nook

- Other

5. Thinking of the technology mentioned previously, which is the single most important piece of technology to you?

6. When thinking about technology and its impact on education, which piece of technology is most important to you?

7. Briefly describe why you chose your answer to the previous question as the most important piece of technology as it impacts education.

8. Education Definition: Education computing is similar to work computing but for specific academic and learning purposes and may involve the use of productivity applications such as Word and Excel. It would also involve the use of learning management systems, such as courses (Blackboard), or library information systems, to access course materials and information online. In an average school year, I use technology for educational purposes...

9. What is the primary device you used for education purposes?

10. Communication Definition: Technology for written and voice communication involves computer programs like Skype, email, text messaging, and social networking via blogs or sites like Facebook. In 
an average school year, I use technology for communication purposes...

11. What is the primary device you used for communication purposes?

12. Entertainment Definition: Technology used for the purposes of entertainment indicates uses such as gaming, viewing videos via websites like YouTube or Hulu, and even some crossover with communication in the sense that websites like Facebook may provide entertainment. In an average school year, I use technology for entertainment purposes...

13. What is the primary device you used for entertainment purposes?

14. Information Gathering Definition (Web-browsing): Technology used for the purposes of information gathering includes visiting websites for news (CNN, New York Times, Reuters), online shopping for goods (clothing, textbooks), or finding needed information, like restaurant reviews or directions. Information gathering is primarily a function of using technology in conjunction with the Internet and is distinct from entertainment (as discussed above) in the sense that entertainment is for personal enjoyment while information gathering is for a purposedriven reason (to be updated on news, find directions to a friend's house). In an average school year, I use technology for information gathering purposes...

15. What is the primary device you used for information gathering purposes?

16. Given my use of all technologies at my disposal, on average I feel I am $\mathrm{a}(\mathrm{n})$ : (expert user, advanced user, intermediate user, novice/basic user, non-technology user)

\section{Post-survey of experience with iPad and interpreting services.}

1. I feel I accomplish more in my student life because of technology. (likert-scale for agreement)

2. If I don't use technology for a week, I feel bothered or out of sorts. (likert-scale for agreement)

3. How often did you use the iPad during group meetings?

4. In general, do you feel your use of the iPad was directly beneficial to you for your participation in the classroom?

5. When thinking about technology and its impact on education, which piece of technology is most important to you?

6. Briefly describe why you chose your answer to the previous question as the most important piece of technology as it impacts education.

7. Education Definition: Education computing is similar to work computing but for specific academic and learning purposes and may involve the use of productivity applications such as Word and Excel. It would also involve the use of learning management systems, such as courses (Blackboard), or library information systems, to access course materials and information online. In an average school year, I use technology for educational purposes...

8. What is the primary device you used for education purposes?

9. Communication Definition: Technology for written and voice communication involves computer programs like Skype, email, text messaging, and social networking via blogs or sites like Facebook. In an average school year, I use technology for communication purposes...

10. What is the primary device you used for communication purposes?

11. Entertainment Definition: Technology used for the purposes of entertainment indicates uses such as gaming, viewing videos via websites like YouTube or Hulu, and even some crossover with communication in the sense that websites like Facebook may provide 
entertainment. In an average school year, I use technology for entertainment purposes...

12. What is the primary device you used for entertainment purposes?

13. Information Gathering Definition (Web-browsing): Technology used for the purposes of information gathering includes visiting websites for news (CNN, New York Times, Reuters), online shopping for goods (clothing, textbooks), or finding needed information, like restaurant reviews or directions. Information gathering is primarily a function of using technology in conjunction with the Internet and is distinct from entertainment (as discussed above) in the sense that entertainment is for personal enjoyment while information gathering is for a purposedriven reason (to be updated on news, find directions to a friend's house). In an average school year, I use technology for information gathering purposes...

14. What is the primary device you used for information gathering purposes?

15. I feel I accomplish more in my student life because of technology. (likert-scale for agreement)

16. If I don't use technology for a week, I feel bothered or out of sorts. (likert-scale for agreement)

17. Given my use of all technologies at my disposal, on average I feel I am $\mathrm{a}(\mathrm{n})$ : (expert user, advanced user, intermediate user, novice/basic user, non-technology user)

18. How often did you use the iPad during one-on-one meetings?

19. In general, do you feel your use of the iPad was directly beneficial to you for your participation in the workplace?

20. How helpful was the iPad in the following situations:

21. I feel I accomplish more in my co-op experience because of technology.

22. What were you biggest challenges in using the iPad?

23. Do you believe others' perceptions of you were changed based on your use of the iPad for accessing services? If so, how? If not, why?

24. Please share any additional information you would like us to know about your experience.

25. Based on the statements above, how likely would you be to use the iPad to access interpreting services in the future?

26. Based on the statements above, how likely would you be to recommend to others the use the iPad to access interpreting services in the future? 


\section{Appendix 2. Supervisor Survey}

Personal Information:

- Gender

- Age group

- Level of education

- Name (optional)

- Name of organization (optional)

Work with deaf and hard of hearing clients and technology.

1. I have previously interacted with deaf or hard of hearing individuals who use a signed language to communicate.

-Yes

-No

2. I have prior experience supervising deaf or hard of hearing employees. -Yes

$-\mathrm{No}$

3. On a scale of 1-10 with 10 being the most comfortable, please rate your comfort level in using mobile technologies and/or devices in the workplace.

4. In reflection, please select a response on your level of agreement to the following statement: I supported my employee utilizing technology as an accommodation in the workplace. (Strongly Disagree, Disagree, Neither Disagree or Agree, Agree, and Strongly Agree)

5. The employee's use of technology in the workplace was obtrusive to daily tasks. (Never, Occasionally, Very Often, Always)

6. Did the use of the mobile technology change your perception of your employee? If not, why? If so, how? 